admitted to the City Hospital, Birmingham, on March 21st, 1893. The eruption consisted of a few papules on the face and forearms, which never developed into true vesicles. She had no symptoms whatever after the appearance of the eruption.

CASE 2.-A boy aged three years and a half. He had not been vaccinated, The patient was admitted to the hospital on March 22nd. The eruption was confluent. He died after great suffering on March 31st. The photograph, of which the engraving is a copy, was taken on March 28th,

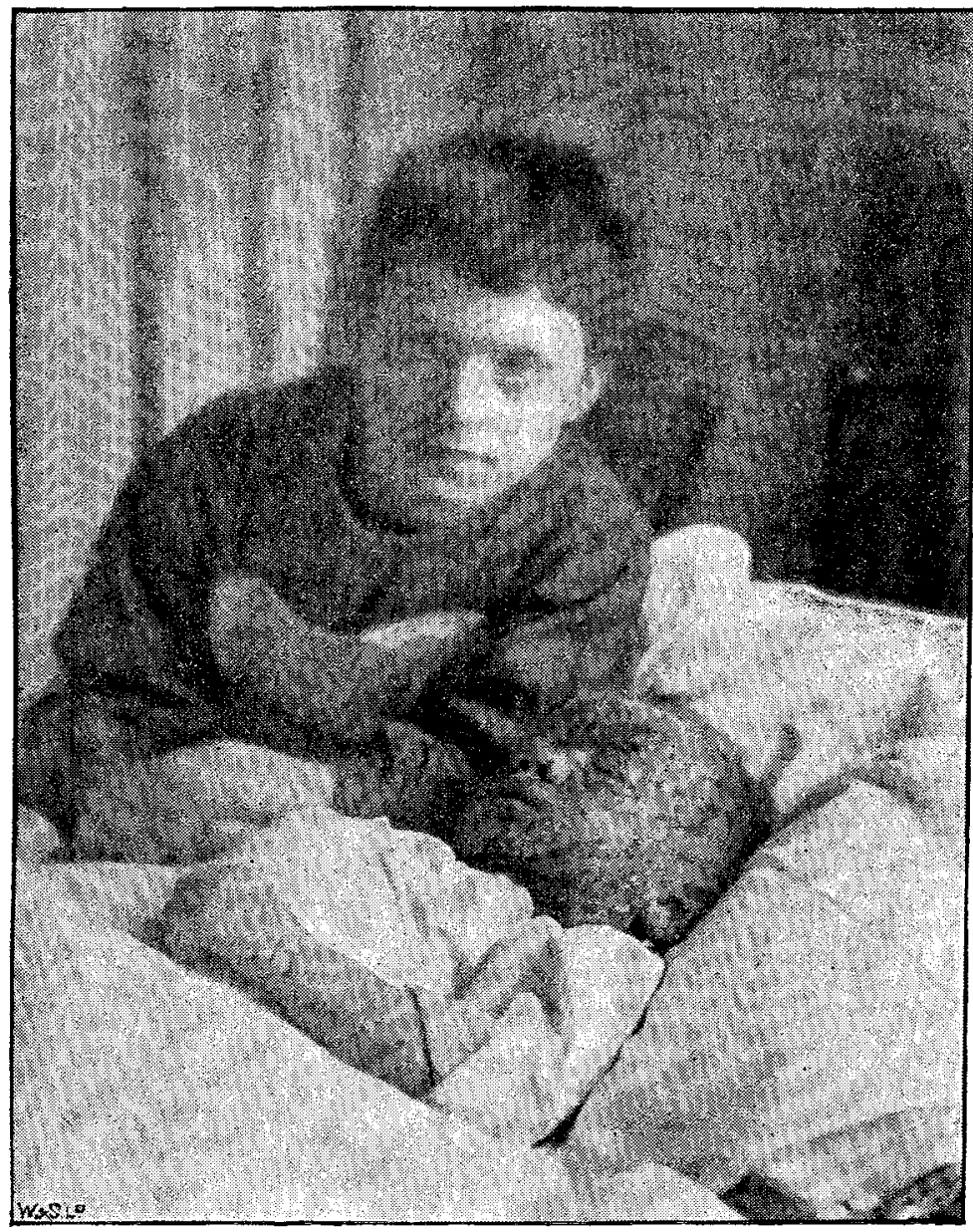

being the thirteenth day of the disease in Case 1 and the tenth day in that of Case 2. The patients, who were sister and brother, contracted the disease from the same source and were subjected to the same surroundings and influences in every particular except that the girl had had an attack of scarlet fever some months previously, from which she was just convalescent.

Birmingham.

\section{GENERAL EMPHYSEMA AS A RESULT OF} PULMONARY TUBERCLE.

BY J. Reginald Fuller, M.R.C.S., L.R.C.P., L.S.A. LoNd, SENIOR RESIDEN'T MEDICAL OFFICER TO THE CHILDREN'S HOSPITAL, BIRMINGHAM.

A CHILD aged four years was admitted to the Children's Hospital on March 14th, 1893, suffering from pulmonary tuberculosis. The family history showed a tuberculous tendency. The present illness had commenced fifteen weeks previously with gradual wasting, cough, sweating and the ordinary signs of tubercle. There was no whooping-cough or any other disease that would cause the child to strain. On admission the patient was much emaciated, and was affected with a constant dry hacking cough and night sweats; but there was no hæmoptysis. On examination there were hurried respiration, impaired resonance at the apices of both lungs and over both backs ; and marked tubular breathing at the back, with moist sounds, and vocal resonance was apparently increased. On March 18th emphysema appeared suddenly, at first in the upper part of the back and neck; thence it spread rapidly to the face, eyelids and forehead, completely closing the eyes, and downwards along the whole trunk to the scrotum, bounded on each side by Poupart's ligament and behind by the rim of the pelvis. The time from the first appearance of the swelling to its full development was under two hours. The whole appearance of the child was altered; he appeared to be nearly twice his previous size. The eyes were quite closed. The swellings about the body were more marked in the flanks and scrotum. Pricking the swellings was followed by re-distension in a very short time. The patient suffered much from dyspnœa ano the cough was very troublesome ; there was no apparent impulse in the swellings upon coughing. The child appeared to. rally somewhat from the shock after stimulation, but after the first night he gradually sank and died on the 21st (three. days after the emphysema commenced), the dyspnoea increas. ing considerably towards the end. The temperature remained normal throughout after the first shock, at which time it fell to $97^{\circ}$. At the necropsy, held on the following morning, the body was found to be almost destitute of subcutaneous fat, though the skin was separated two inches or more in places by the extravasated air from the deeper structures. On opening the chest no fluid was found in the pleural cavities; both lungs were slightly adherent to the parietes, more so behind than in front, but neitherlung was much collapsed. The mediastinal glands were enlarged, caseous, and breaking down. Botb apices were almost solid with tuberculous masses, and miliary tubercles were scattered throughout both lungs. The left upper lobe was found to be partly adherent to one large gland, which was in turn fixed to the parietes; this gland was broken down in the centre, and a probe could be passed through it into the cellular tissue. No cavity in the lung could be discovered, though the communication was doubtless established by the ulceration and breaking down of the cells at the situation of this gland.

Birmingham.

\section{DISLOCATION OF THE HIP IN A CHILD THREE YEARS OF AGE.}

By Surgeon-Major D. Charles Dafidson, I.M.S., CIVIL SURGEON, SATARA, INDIA.

A Hindoo cHILD about three years of age was brought to the Civil Hospital, Satara, on March 31st last with a deformity of the hip. The history was obscure. It was stated that the child whilst playing fell down on a stone and sustained the injury for which he was brought to the hospital, but nothing very clear or definite could be elicited. This was said to have occurred more than a fortnight previously to admission. On a careful examination he was founc to be suffering from dislocation of the right hip-joint of the ilio-sciatic type. The child was placed under chloroform and the dislocation was reduced by manipulation with some little difficulty.

Remarks. - The chief feature of interest in this case is the great rarity of dislocation of the hip-joint in young children.

\section{TERTIAN AGUE OCCURRING DURING AN ATTACK OF ENTERIC FEVER.}

BY T. SYDNEY SHORT, M.D. LOND.

IT is always interesting to note occasions when two maladies attack the human frame at the same time and to watch the result that accrues. The following case illustrates an attack of tertian ague occurring during the course of enteric fever.

The patient, a healthy young man aged twenty-nine, hac formerly been in the army in India and had suffered on two occasions from ague when there. Since his return to England four years ago he had been quite free from it. During the third week of what appeared to be in all respects a typical attack of enteric fever he had a rigor, with the temperature rising to $104^{\circ}$, followed by profuse sweating and a rapid fall of the temperature to $95.2^{\circ}$, as taken in the rectum. This naturally gave rise to alarm, but he himself said with a calmness that was reassuring, "It's only an attack of the ague " I had it four years ago in India." The temperature rose again the next day without any rigor, but the day after he had another rigor, the temperature reaching nearly $105^{\circ}$, followed by a fall to $95 \cdot 6^{\circ}$. Quinine had been exhibited and 
from this time the fever ran an ordinary course, and he made a good recovery. It is interesting to note that in spite of the high temperature his pulse was never higher than 104.

The temperature from Oct. 29th to Nov. 4th had gradually fallen to $100^{\circ} \mathrm{F}$., when it suddenly rose to $104^{\circ}$, falling on Nor. 5th to $95.2^{\circ}$, and rising again to $103.6^{\circ}$. On the 6th it is noted as having fallen to $98^{\circ}$ and as rising again to its highest point, $1046^{\circ}$, whence on the 7 th it fell to $95.6^{\circ}$ and then rose to the normal enteris fever level of $102^{\circ}$, whence defervescence gradually established itself, and the temperature then fell to the usual post-febrile subnormal range between $97^{\circ}$ and $98^{\circ}$.

Newhall-street, Birmingham.

\section{ETHER IN PERCUTANEOUS THERAPEUTICS.}

By Sir James SAwYer, M.D.Lond., F.R.C.P., F.R.S. EdiN., CONSULTING PHYSICIAN TO THE QUEEN'S HOSPITAL, BIRMINGHAM.

I HAVE asked Messrs. Southall to seek for further useful applications of the employment of ether as a menstruum in medication by the skin, in the preparation of recognised remedies, beyond those to which $I$ have already invited professional attention. ${ }^{1}$ After careful examination of the subject and many experiments they have proposed to me the following modifications of officinal formulæ-namely: 1. Linimentum camphoræ æthereum (same strength as B.P. liniment): camphor., 1 ; ol. olivæ, $\frac{1}{2}$; æther., $3 \frac{1}{2}$ ( 1 in five). 2. Linimentam crotonis æther. (same strength as B.P. liniment): Ol. croton., 1 ; ol. cajuput., $3 \frac{1}{2}$; æ2ther., $3 \frac{1}{2}$. 3 . Linimentum sinapis co. æether. (same strength as B.P. liniment) : Ol. sinapis, 3 ; ext. mezerei æther., 2 ; camphor., 6 ; ol. ricini, 15 ; æther., 96 ( 1 in 40). An ethereal pigment of stavesacre may be prepared from stavesacre seeds, of the same strength as the officinal ointment. It might also be useful to substitute an ethereal pigment of veratrine for the ointment of veratrine in the Pharmacopoia. I have lately used these new ethereal preparations in practice and I have been especially pleased by the efficiency, cleanliness and ready applicability of the ethereal liniment of croton oil.

Temple.row, Birmingham.

\section{9 attirutor}

\section{HOSPITAL PRACTICE, BRITISH AND FOREIGN.}

Nulla autem est alia pro certo noscendi via, nisi quamplurimas et morborum et dissectionum historias, tum aliorum tum proprias collectas habere, et inter se comparare.-MoRGAGNI De Sed. et Caus. Morb., lib. iv. Procmium.

\section{ST. THOMAS'S HOSPITAL.}

TORSION OF COLON IN THE SAC OF AN UMBILICAL HERNIA; GANGRENE OF THE GUT' RESECTION OF THF GREATER PART OF THE TRANSVERSE COLON ; ESTABLISHMENT OF AN ARTIFICIAL ANUS; RECOVERY.

(Under the care of Mr. G. H. M. Mariss.)

THIs case is an example of obstruction of the bowels in which the obstruction, although situated in a hernial sac, was not caused in the usual manner by constriction of or near the neck of the sac, but by a volvulus or twisting of the contents. There are two ways in which a volvulus of the bowel takes place: (1) Twisting round a mesenteric axis ; (2) the intertwining of two coils of intestine so that obstruction is caused by it ; of these the former is the more common. We cannot enter here into a discussion as to the advisability or otherwise of excision as opposed to the formation of an artificial anus in gangrene of intestine due to strangulation. Each case should be considered on its merits and treatment adopted accordingly.

The patient, a married woman aged seventy-nine, the mother

1 The Lancet, May 17th and July 12th, 1890. of eight children, was admitted to $\mathrm{S}$ t. 'Thomas's Hospital on Nov. 27th, 1892. She has had a reducible umbilical hernia for many years, but always enjoyed excellent general health. While walking upstairs to bed at 9 P.M. she was seized with sudden pain in the abdomen and commenced to vomitcopiously. Four hours and a half later she was brought to the hospital and the following condition was noted on admission. She was partly unconscious, in very severe pain and vomited frequently; the tongue was moist but furred; the bowels acted the day before admission; the temperature was normal, the pulse small and rapid; the hernia was of considerable size; the umbilicus was situated at the lower part of the tumour, it was tense, dull on percussion and very tender. At 4 A.M., seven hours after the commencement of the symptoms, the patient was placed under the influence of mixed ether and chloroform anæsthesia. An incision four inches in length was carried through the wall of the hernia, the colon at once came into view and a very fetid odour was noticeable. The gut was devoid of polish, dark purple (in parts greenish) in colour, and evidently gangrenous. On examining the ring it was found that the finger could be passed into the abdominal cavity and that the gut was in no way compressed at the neck. The colon, however, was very fully distended with fæces and the loop had undergone a half turn on it mesentery, giving rise to complete obstruction of its lumen at a point corresponding to the neck of the hernial sac. As the appearance of the intestine offered no prospect of recovery the sac was well flushed, the gut was drawn out, the neck packed, clamps applied to the healthy gut on the proximal and distal side, and the affected loop cut off. Ligatures were applied to the mesenteric vessels, and the two ends of the intestine were sutured side by side near the mesenteric margin. A portion of the redundant sac was excised, and the gut was then stitched with a continuous suture to the abdominal wall, so as to form an artificial anus. The portion of colon removed consisted of the transverse colon, which, as the result of distension, was $U$ shaped. The walls were gangrenous, and the lumen was fully distended with solid fæces, of which this portion of the gut had evidently been the habitual reservoir. The after-conrse of the case was satisfactory in the extreme. The temperature never rose to $100^{\circ}$ except on the first night, afterwards running an untnterruptedly normal course. Locally, slight suppuration occurred in the remains of the old sac, but four weeks later the patient was able to wear an indiarubber colotomy plug with comfort, and she left the hospital in good health on Jan. 2nd, 1893.

Remarks by Mr. MAKINS. - The above case is of interest both from its rarity and from the fact that the advanced age of the patient did not interfere with a satisfactory result. The most striking point in the history was the rapidity with which gangrene of the affected intestine took place, and this evidence of low vitality was an important point in deciding the best line of treatment to adopt. The occurrence of torsion. seems readily explicable when the conditions are reviewed. The colon formed a well-marked loop attached to an elongated mesentery, the loop was heavily distended with fæces and escaped through a large opening in the abdominal wall free enough to allow the twist to take place with ease. The weight of the contained fæces taken with the elongation of the mesentery would offer unusually favourable conditions for the accident. As to the treatment adopted, the age of the patient, the rapid occurrence of gangrene in the affected intestine, and the necessity for rapid completion of the operation, seemed to contraindicate any attempt to immediately unite the ends of the divided colon, and the same reasons rendered the patient an unsuitable subject for further surgical interference at a later date, although she left the hospital bright and cheerful and in good condition.

\section{ROYAL INFIRMARY, NEWCASTLE-ON-TYNE。} FOUR CONSECUTIVE CASES OF NEPHRECTOMY.

(Under the care of Mr. PAgE.)

In these four cases of removal of the kidney for disease the operation selected was that by the lumbar method, the one which is generally performed where hydronephrosis or pyonephrosis requires it. The difficulty met with in removing the kidney varied in the different cases; in one the organ was much adherent and was separated with much trouble and not without wound of the peritoneum. The complication of 